Tropical Journal of Pharmaceutical Research October 2018; 17 (10): 2067-2072

ISSN: $1596-5996$ (print); 1596-9827 (electronic)

(c) Pharmacotherapy Group, Faculty of Pharmacy, University of Benin, Benin City, 300001 Nigeria.

\title{
Use of herbal medicines in a Nigerian community and their reported adverse effects: A pilot study
}

\author{
Kosisochi Chinwendu Amorha*, Ifeoma Amarachukwu Nwabunike ${ }^{2}$, Basil \\ Moses Okwumuo ${ }^{2}$, Ebere Emilia Ayogu', Sunday Odunke Nduka ${ }^{3}$, Mathew \\ Jegbefume Okonta ${ }^{1}$ \\ ${ }^{1}$ Department of Clinical Pharmacy and Pharmacy Management, University of Nigeria, Nsukka, Enugu State, ${ }^{2}$ Department of \\ Pharmacology and Toxicology, University of Nigeria, Nsukka, Enugu State, ${ }^{3}$ Department of Clinical Pharmacy and Pharmacy \\ Management, Nnamdi Azikiwe University, Awka, Anambra State, Nigeria
}

*For correspondence: Email: kosisochi.amorha@unn.edu.ng; Tel: +234-8038539349

Sent for review:

Revised accepted: 28 April 2018

\begin{abstract}
Purpose: To evaluate the use of herbal medicines in Nsukka community and determine the adverse reactions associated with this practice.

Methods: A cross-sectional survey of 120 persons was conducted in Ogige market, Nsukka using selfadministered questionnaires. Outcomes measured included proportion of respondents who use herbal medicines and their reasons, their perception on the safety and effectiveness of the medicines, their purchasing habits of the medicines, those who recommend the medicines, and adverse reactions to them. Frequency analysis and Pearson's correlation test were conducted with statistical significance set at $p<0.05$.

Results: Less than half of the respondents (43.2\%) took herbal medicines without consulting a health professional, and more than $60 \%$ of them believed that herbal medicines are safe and effective. Only $47.4 \%$ of the respondents claimed to have ever experienced mild adverse effects following the use of the medicines which were resolved with advice sought from health professionals. Stooling and vomiting were the major reported adverse effects. Older respondents had a better perception on the safety of herbal medicines $(p=0.005)$ and are less likely to tell their health professionals that they are already taking herbal medicines when orthodox medicines are prescribed/recommended for them. High-income earners spent more on herbal medicines $(p=0.029)$ than others.

Conclusion: Many respondents use herbal medicines without consulting a health professional. However, most of them seek advice from health professionals when adverse effects result from these medicines during use.
\end{abstract}

Keywords: Adverse effects, health professionals, herbal medicines use, Nsukka community

This is an Open Access article that uses a funding model which does not charge readers or their institutions for access and distributed under the terms of the Creative Commons Attribution License (http://creativecommons.org/licenses/by/4.0) and the Budapest Open Access Initiative (http://www.budapest openaccessinitiative.org/read), which permit unrestricted use, distribution, and reproduction in any medium, provided the original work is properly credited.

Tropical Journal of Pharmaceutical Research is indexed by Science Citation Index (SciSearch), Scopus, International Pharmaceutical Abstract, Chemical Abstracts, Embase, Index Copernicus, EBSCO, African Index Medicus, JournalSeek, Journal Citation Reports/Science Edition, Directory of Open Access Journals (DOAJ), African Journal Online, Bioline International, Open-J-Gate and Pharmacy Abstracts

\section{INTRODUCTION}

The World Health Organization (WHO) defined herbal medicines as "herbs, herbal materials, herbal preparations and finished herbal products that contain as active ingredients parts of plants, or other plant materials, or combinations" [1]. Although, herbal medicines may be produced from any part of the plant, they are commonly made from the leaves, roots, bark, seeds, and 
flowers [3]. The herbs are eaten, swallowed, drunk, inhaled, or applied to the skin [2]. In spite of the great advances observed in modern medicine in recent decades, medicinal plants still play a key role in world health [4].

The interest in plant remedies has been spurred by several factors including their effectiveness, the high cost and side effects of orthodox medicines, improvements in the quality, safety, and efficacy of herbal medicines with the development of science and technology, selfmedication, and the belief that herbal medicines might be effective in the treatment of any disease where conventional therapies have failed [4-6]. In most countries, herbal products do not have to meet the quality control measures applicable to orthodox medicines [3]. While they may be useful in treating different ailments [7-9], they may be associated with various adverse reactions. This absence of uniform product standardization has raised some concerns $[11,12]$.

The increasing numbers of internet websites that sell and promote herbal supplements have exposed unsuspecting consumers to inaccurate claims regarding these products $[3,10]$. In Nigeria, the use of vehicles with loudspeakers for advertising herbal products in villages, towns and cities is common. Many patients in Enugu use a wide range of herbal medicines in addition to their conventional medicines [13], without informing their healthcare providers about the concomitant use of the herbs with orthodox medicines. Some healthcare professionals also do not ask questions about their use of herbal medicines due to inadequate knowledge about their use [11]. Therefore, the objective of this study was to ascertain the use of herbal medicines by Nsukka community in Enugu State and to determine adverse reactions associated with this practice.

\section{METHODS}

This study was a cross-sectional and descriptive survey carried out in Ogige market, Nsukka Local Government Area, Enugu State. Nsukka is located about $70 \mathrm{~km}$ North of Enugu in SouthEastern Nigeria. It is the second biggest town in Enugu State and hosts the first indigenous Nigerian university, University of Nigeria, Nsukka. The Ogige market is Nsukka's largest market and it attracts not only residents of the local government area but also the surrounding local government areas, towns and States, such as Kogi and Benue States.

For this pilot study, 120 respondents were conveniently sampled from five sections of the study area. Respondents were restricted to those who were 18 years and above. Those who could not communicate in English were excluded from the study.

Data were collected using a 34-item structured self-administered questionnaire which was given to consenting participants to fill out. The statements in the instrument were modified from previously validated questionnaires to suit the study area. Information sought in the questions included respondents' sociodemography, use of herbal medicines and the reasons, perception on the safety and effectiveness of herbal medicines, their purchasing habits of the medicines, those who recommend them, and adverse reactions to them. Oral consent was obtained before issuing the survey instrument. Willingness to participate in the study was taken as consent and participants were informed that they were free to withdraw at anytime. Confidentiality was maintained as the names of the respondents were not requested.

\section{Data analysis}

Data was coded and entered into the Statistical Package for Social Sciences (SPSS) Windows version 16.0 (SPSS Inc, Version 16, Chicago, USA) for analysis. Frequency analysis was conducted for the demographics. Data were analyzed by Pearson Correlation test with statistical significance set at $p<0.05$.

\section{RESULTS}

\section{Demographic characteristics and participa- tion rates}

A total of 93 questionnaires were completed and returned, representing a participation rate of $77.5 \%$. Most of the respondents were below 40 years of age $(78.9 \%)$. Majority of them were literate with $80.9 \%$ having either a Diploma or Bachelor degree. More than half of them were self-employed $(67.0 \%)$, mainly as traders $(58.0 \%)$. Most respondents $(56.9 \%)$ claimed to earn less than $\$ 50,000$ monthly (Table 1 ).

More than half of the respondents claimed to have taken herbal medicines in the past 12 months but only about a quarter of them preferred herbal medicines to orthodox medicines (Table 2). More than half of the respondents perceived herbal medicines as safe and effective (Table 3).

More than half of the respondents who use herbal medicines reported spending less than \#500 monthly (US\$1.0 $=\$ 363.00$ ) on the 
Table 1: Demographics of respondents in the survey $(\mathrm{N}=93)$

\begin{tabular}{|c|c|}
\hline VARIABLE & $\begin{array}{l}\text { NUMBER OF } \\
\text { RESPONSES (\%) }\end{array}$ \\
\hline \multicolumn{2}{|l|}{ Age (in years) } \\
\hline $18-29$ & $45(50.0)$ \\
\hline $30-39$ & $26(28.9)$ \\
\hline $40-49$ & $18(20.0)$ \\
\hline $50-59$ & $1(1.1)$ \\
\hline$>60$ & $0(0.0)$ \\
\hline \multicolumn{2}{|l|}{ Gender } \\
\hline Male & $46(51.1)$ \\
\hline Female & $44(48.9)$ \\
\hline \multicolumn{2}{|l|}{ Marital Status } \\
\hline Single & $49(55.1)$ \\
\hline Married & $36(40.4)$ \\
\hline Divorced & $1(1.1)$ \\
\hline Separated & $2(2.2)$ \\
\hline Widowed & $1(1.1)$ \\
\hline \multicolumn{2}{|l|}{ Religion } \\
\hline Christianity & $72(80.0)$ \\
\hline Islam & $2(2.2)$ \\
\hline Traditional & $5(5.6)$ \\
\hline Others & $11(12.2)$ \\
\hline \multicolumn{2}{|l|}{ Highest Level of Education } \\
\hline Did not go to school & $2(2.2)$ \\
\hline Primary school & $2(2.2)$ \\
\hline Secondary school & $11(12.4)$ \\
\hline Diploma & $28(31.5)$ \\
\hline Bachelor degree & $24(49.4)$ \\
\hline Postgraduate degree & $2(2.2)$ \\
\hline \multicolumn{2}{|l|}{ Current work status } \\
\hline Self-employed & $59(67.0)$ \\
\hline Employed full-time & $8(9.1)$ \\
\hline Employed part-time & $8(9.1)$ \\
\hline Unemployed & $13(14.8)$ \\
\hline \multicolumn{2}{|l|}{ Occupation } \\
\hline Farming & $1(1.2)$ \\
\hline Trading & $47(58.0)$ \\
\hline Professional & $17(21.0)$ \\
\hline Others & $16(19.8)$ \\
\hline \multicolumn{2}{|l|}{ Income Level Per Month } \\
\hline$<\# 10,000$ & $8(10.1)$ \\
\hline$\# 10,000$ to $<\# 50,000$ & $37(46.8)$ \\
\hline$\# 50,000$ to $<\notin 100,000$ & $19(24.1)$ \\
\hline$\# 100,000$ to $<\# 150,000$ & $14(17.7)$ \\
\hline$>\notin 150,000$ & $1(1.3)$ \\
\hline
\end{tabular}

Table 2: Reported use of herbal medicines by respondents

\begin{tabular}{ll}
\hline VARIABLE & N (\%) \\
\hline $\begin{array}{l}\text { Used herbal medicines previously } \\
\text { Used herbal medicines in the past } 12\end{array}$ & $59(71.1)$ \\
$\begin{array}{l}\text { months } \\
\text { Prefer herbal medicines to orthodox } \\
\text { medicines }\end{array}$ & $53(65.4)$ \\
\hline
\end{tabular}

medicines with most recommendations coming from family members or friends (Table 4 and Table 5).

Stooling and vomiting were the two most common adverse effects the respondents experienced with herbal medicines (Figure 1). Most adverse reactions to herbal medicines experienced by the respondents were mild and majorly resolved by seeking advice from healthcare professionals (Table 6).

Table 3: Respondents' opinion on the effectiveness and safety of herbal medicines

\begin{tabular}{ll}
\hline VARIABLE & N (\%) \\
\hline Effectiveness & \\
Very effective & $5(5.9)$ \\
Somewhat effective & $53(62.4)$ \\
Not effective & $2(2.4)$ \\
Not sure & $25(29.4)$ \\
Safety & $5(5.8)$ \\
Very safe & $47(54.7)$ \\
Somewhat safe & $5(5.8)$ \\
Not safe & $29(33.7)$ \\
Not sure & \\
\hline
\end{tabular}

Table 4: Expenses on herbal medicines and reasons for their use

\begin{tabular}{|c|c|}
\hline VARIABLE & $\mathbf{N}(\%)$ \\
\hline \multicolumn{2}{|c|}{ Monthly expenditure on herbal medicines } \\
\hline Up to 500 & $35(55.6)$ \\
\hline \#00 to less than 1000 & $9(14.3)$ \\
\hline A 1000 to less than 5000 & $19(30.2)$ \\
\hline more than 5000 & $0(0.0)$ \\
\hline \multicolumn{2}{|l|}{$\begin{array}{l}\text { Reason respondents take herbal } \\
\text { medicines }\end{array}$} \\
\hline It keeps me healthy & $54(72.0)$ \\
\hline To prevent disease & $52(68.4)$ \\
\hline To treat a specific disease or symptom & $36(49.3)$ \\
\hline It fits into my way of life & $23(30.7)$ \\
\hline $\begin{array}{l}\text { Health problem is not serious enough } \\
\text { to take prescription medicines }\end{array}$ & $34(44.7)$ \\
\hline $\begin{array}{l}\text { They work better or just as well as } \\
\text { other medicines }\end{array}$ & $40(53.3)$ \\
\hline $\begin{array}{l}\text { They were recommended to me } \\
\text { It gives me a sense of control over my }\end{array}$ & $28(37.3)$ \\
\hline health & $35(46.1)$ \\
\hline Thev have few side effects & $25(33.3)$ \\
\hline
\end{tabular}

Table 5: Recommendation of herbal medicines

\begin{tabular}{ll}
\hline VARIABLE & N (\%) \\
\hline $\begin{array}{l}\text { Those who recommend herbal } \\
\text { medicines to respondents } \\
\text { Doctors }\end{array}$ \\
Nurses & $3(4.1)$ \\
Pharmacists & $0(0.0)$ \\
Pharmacy Assistants & $1(1.4)$ \\
Family/Friends & $0(0.0)$ \\
Self & $44(59.5)$ \\
Patent and Proprietary Medicine & $21(28.4)$ \\
Vendors & \\
Herbalists/Traditional Healers & $1(1.4)$ \\
Not Sure & $1(1.4)$ \\
\hline
\end{tabular}




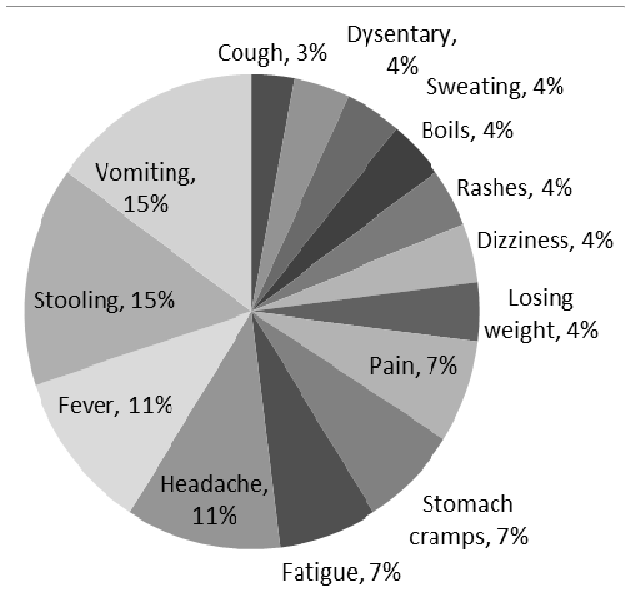

Figure 1: Major adverse effects experienced with herbal medicines as reported by respondents

Most respondents who use the herbal medicines obtained their products mainly through the different individuals and companies operating under the 'networking business approach' with community pharmacies rarely patronized either due to inconvenience or higher cost (Table 7).

\section{DISCUSSION}

This study has revealed that more than $50 \%$ of those evaluated used herbal medicines with

Table 6: Adverse reactions to herbal medicines

\begin{tabular}{ll}
\hline VARIABLE & $\mathbf{N}(\%)$ \\
\hline Ever experienced an adverse reaction to a herbal medicine & $37(47.4)$ \\
Seriousness of the reaction & \\
Severe (required hospitalization) & $3(5.7)$ \\
Moderate (symptoms required a visit to a doctor or other healthcare professional) & $2(3.8)$ \\
Mild (no specific treatment was required) & $28(52.8)$ \\
Not applicable & $20(37.7)$ \\
Those informed about the adverse reaction & $6(11.1)$ \\
I didn't tell anyone & $2(3.7)$ \\
A doctor & $1(1.9)$ \\
A pharmacist & $2(3.7)$ \\
A pharmacy assistant & $5(9.3)$ \\
Family/friends & $2(3.7)$ \\
Rang a professional help line (e.g. NAFDAC) & $16(29.6)$ \\
The product manufacturer & $20(37.0)$ \\
Not applicable & \\
How respondents handled the adverse reaction & $6(11.1)$ \\
I stopped using the product which I think caused it & $1(1.1)$ \\
I reduced the dose I was taking & $1(1.1)$ \\
I changed to another herbal medicine & $21(38.9)$ \\
I sought advice from a healthcare professional & $25(46.3)$ \\
Not applicable &
\end{tabular}

Table 7: Purchasing habits of respondents

\begin{tabular}{ll}
\hline VARIABLE & $\mathbf{N}(\%)$ \\
\hline Where respondents purchase their herbal medicines & $10(14.9)$ \\
Pharmacy & $6(9.0)$ \\
Internet & $5(7.5)$ \\
Hospital/Clinic & $31(46.3)$ \\
Networking & $15(22.4)$ \\
Others & $19(26.8)$ \\
Major reasons respondents don't purchase herbal medicines from a pharmacy & $5(7.0)$ \\
It is too expensive & $3(4.2)$ \\
They don't have the specific product I want & $8(11.3)$ \\
I get better advice about these products elsewhere & $19(26.8)$ \\
I don't need pharmacists' advice about these products & $17(24.0)$ \\
It is not convenient for me & \\
Not applicable & \\
Others & $0(0.0)$ \\
Major reasons respondents purchase herbal medicines from a pharmacy & $2(3.3)$ \\
It is cheaper than elsewhere & $15(24.6)$ \\
They have the specific product I want & $12(19.7)$ \\
I get better information about herbal medicines from the pharmacy than elsewhere & $30(49.2)$ \\
It is convenient for me & $2(3.3)$ \\
Not applicable & \\
Others & \\
\hline
\end{tabular}


many of them perceiving the medicines as safe and effective. For those who used the medicines, less than 5000 was spent monthly on them. While the main source of these medicines was vendors operating under the 'network sales groups, the medicines were mainly recommended for the users by family members or friends. Stooling and vomiting were the two most common adverse effects reported by the users while most adverse reactions experienced by the respondents were mild and often resolved by seeking advice from healthcare professionals.

In this study, older respondents had a better perception on the safety of herbal medicines and are less likely to tell their health professionals that they are already on herbal medicines when orthodox medicines are prescribed/recommended for them.

Although the use of the herbal medicines is popular, more than half of the respondents spent less than $\$ 500$ monthly on the medicines most probably because of their poor earnings as majority of them earned below 50,000 monthly. The high rate of the use of herbal medicines is similar to that earlier reported $[14,15]$ possibly due to the perception that these medicines are more cost-effective and safer than orthodox medicines. The low proportion of the respondents that reported using the medicines at the recommendation of their physicians is equally similar to what of earlier reported [14] signifying that most herbal medicine users have other drivers for utilizing herbal medicines besides health care professionals or assistants. The reliance on family members or friends to recommend the use of herbal medicine as observed in this study follows the path of traditional use of medicines as most of them did not feel they require advice from a health professional to use herbal medicines [14]. The perceived safety and effectiveness of the medicines by the users and the fact that most of them sought advice from a health professional when they experience adverse effects greatly supports this assumption.

Some studies have reported poor knowledge of the pharmacists in the phytopharmaceuticals sold in pharmacies indicating an urgent need for intensive training in order to render better services to their clients $[13,16]$. If community pharmacists cannot meet the health care needs of patients as regards herbal medicines, these patients may resort to other less credible sources. To encourage the informed use of herbal medicines there is a need for the development of accessible, quality resources on herbal medicines. Also, incorporation of complementary medicines into pharmacy curricula would better prepare graduate pharmacists for community practice and ultimately, contribute to the safe and effective use of herbal medicines to the benefit of consumers [17]. Self-medication should not be discouraged in totality but should be practiced under controlled conditions and community pharmacists who are usually readily accessible may help to ensure safe self-medication practices [18,19]. Obviously, the results of this study cannot be directly generalized to other towns, cities or states in Nigeria. However, complementary medicines are now commonplace in Nigeria and this study opens channels for further research in the use of these medicines in Nigeria.

\section{CONCLUSION}

Herbal medicines are widely used in Nsukka community but are hardly purchased from the community pharmacies or obtained from hospitals/clinics. Although some users may experienced stooling and vomiting, the adverse reactions to the herbal medicines were mostly mild and resolved with advice sought from healthcare professionals. Knowing that herbal medicines are frequently used by many people, it becomes important that patients are encouraged to consult healthcare professionals (especially pharmacists who are the experts on medicines) prior to use of herbal medicines rather than only when there are adverse reactions to the medicines. The need for the pharmacists to regularly update their knowledge on complementary medicines through symposia, conferences, update lectures etc is of the essence. The findings in this works calls for urgent need for the government to quickly apply measures that will eliminate the sale of herbal medicines by non-healthcare professionals.

\section{DECLARATIONS}

\section{Acknowledgement}

The authors sincerely thank all the respondents as they were drawn out of their busy schedules to participate in the study.

\section{Conflict of interest}

The authors have no conflict of interest to declare.

\section{Authors' contribution}


AKC and IAN conceived the study, designed the study and questionnaire and drafted the manuscript. AKC performed the statistical analysis. BMO participated in the design of the questionnaire and was actively involved in the data collection phase. EEA performed the data entry and reviewed the manuscript. SON reviewed the statistical analysis and manuscript. MJO reviewed the manuscript for submission.

\section{REFERENCES}

1. World Health Organization (WHO). Traditional medicine: definitions, 2016 [cited 2016 Jan 20]. Available from: http://www.who.int/medicines/areas/traditional/definition s/en/.

2. Akerele O. Summary of WHO guidelines for the assessment of herbal medicines. HerbalGram 1993;28:13.

3. Bandaranayake, Wickramasinghe M. Quality control, screening, toxicity, and regulation of herbal drugs. In: Ahmad, I; Aqil, F; Owais, M, editors. Modern phytomedicine: turning medicinal plants into drugs. Germany: Wiley-VCH Verlag $\mathrm{GmbH}$ \& Co. KGaA, Weinheim;2006. p.25-57.

4. Calixto JB. Efficacy, safety, quality control, marketing and regulatory guidelines for herbal medicines (phytotherapeutic agents). Braz J Med Biol Res 2000;33(2):179-189.

5. World Health Organization (WHO). Monographs on selected medicinal plants, volume 2 Geneva: World Health Organization, 2002 [cited 2016 Jan 21]. Available from: $h$ ttp://www.who.int/medicedocs/en/d/Js4927e/.

6. Kong JM, Goh NK, Chia LS, Chia TF. Recent advances in traditional plant drugs and orchids. Acta Pharmacol Sin 2003;24:7.

7. Mukherjee PK, Saritha GS, Suresh B. Antimicrobial potential of two different Hypericum species available in India. Phytother Res 2002;16(7):692-695. Doi:10.1002/ptr.1016.

8. Okoli RI, Aigbe O, Ohaju-Obodo JO, Mensah JK. Medicinal herbs used for managing some common ailments among Esan people of Edo State, Nigeria. Pak. J. Nutr 2007;6(5):490-496.

9. Gratus C, Wilson S, Greenfield SM, Damery SL, Warmington SA, Grieve R, Steven NM, Routledge $P$.
The use of herbal medicines by people with cancer: a qualitative study. BMC Complement Altern Med 2009;(9) 14

10. Oshikoya KA, Senbanjo IO, Njokanma OF, Soipe A. Use of complementary and alternative medicines for children with chronic health conditions in Lagos, Nigeria. BMC Complement Altern Med 2008;8:66. doi:10.1186/14726882-8-66.

11. Miller LG, Hume A, Harris IM, Jackson EA, Kanmaz TJ, Cauffield JS, Chin TWF, Knell M. White paper on herbal products. Pharmacotherapy 2000;20(7):877-891.

12. Mukherjee PW. Quality control of herbal drugs: an approach to evaluation of botanicals. New Delhi, India: Business Horizons Publishers;2002.

13. Adisa R, Fakeye T. Assessment of the knowledge of community pharmacists regarding common phytopharmaceuticals sold in South Western Nigeria. Trop. J. Pharm. Res 2006;5(2):619-625.

14. Hwee-Ling K, Hui-Ling N, Hsiao-Huei T. A survey on knowledge, attitudes and usage of complementary and alternative medicine in Singapore. Asia-Pacific Biotech News 2004;8(23):1266-1270.

15. Braun LA, Tiralongo E, Wilkinson JM, Spitzer O, Bailey M, Poole S, Dooley M. Perceptions, use and attitudes of pharmacy customers on complementary medicines and pharmacy practice. BMC Complement Altern Med 2010;10:38.

16. Semple SJ, Hotham E, Rao D, Martin K, Smith CA, Bloustien GF. Community pharmacists in Australia: barriers to information provision on complementary and alternative medicines. Pharmacy World and Science 2006;28(6):366-373.

17. Culverhouse SE, Wohlmuth $H$. Factors affecting pharmacists' recommendation of complementary medicines - a qualitative pilot study of Australian pharmacists. BMC Complement Altern Med 2012;12:183.

18. Fakeye TO, Adisa R, Showande SJS. Attitude and opinion of Nigerian community pharmacists to selfmedication practices. Afr. J. Pharm. Pharmacol 2012; 6(15):1147-1152.

19. Alkharfy KM. Community pharmacists' knowledge, attitudes and practices towards herbal remedies in Riyadh, Saudi Arabia. East Mediterranean Health Journal 2010;16(9):988-993. 